\title{
L’Âge classique français dans les périodisations littéraires
}

\author{
Nermin Vučelj \\ Faculté de Philosophie, Université de Niš*
}

Le dessein de cette recherche est d'analyser comment l'âge classique français est considéré dans l'histoire et la théorie littéraires, et quel cadre temporel lui attribuent les théoriciens, de la fin du XIX ${ }^{\mathrm{e}}$ siècle - avec Gustave Lanson (1896), et tout au long du xx ${ }^{\mathrm{e}}$ siècle - dans Bédier-Hazard (1923), Castex-Surer (1947), Lagarde-Michard (1962), dans la collection littéraire d'Arthaud (Adam, Clarac, Pomeau, 1968-1971), dans celle des Itinéraires littéraires (Horville, 1988), dans celle de Nathan dirigé par Jean Rohou (1989), jusqu'au début du Xxi ${ }^{\mathrm{e}}$ siècle - dans Le Classicisme d'Alain Génetiot (2005), dans l'ouvrage collectif Histoire de la France littéraire (2006), chez les théoriciens Zékian (2012) et Viala (2015). Cette analyse se réfère aussi aux études soviétiques (1946) et yougoslaves (1976) relatives au sujet. Le présent article revalorise les théories concernant l'âge classique français dans le dessein de susciter de nouvelles considérations de cette époque de la littérature française.

Mots-clés : âge classique français, XVII ${ }^{\mathrm{e}}$ siècle, classicisme, périodisation littéraire, théorie de la littérature, histoire littéraire.

\section{Introduction}

La classification diachronique de la littérature est la périodisation historique des Lettres ayant pour but de faciliter la description et de permettre la compréhension de la littérature, de ses débuts connus jusqu'à présent. Ainsi la périodisation littéraire sert-elle à saisir les caractéristiques communes de la littérature des époques distinguées et des périodes désignées. Pourtant, étant une convention théorique, toute périodisation des Lettres est relative et changeable, y compris la classification de la littérature française du XVII ${ }^{\mathrm{e}}$ siècle, l'époque que l'on qualifie usuellement de « classique ».

*nermin.vucelj@filozofski.rs

Cet article est rédigé dans le cadre du projet scientifique Les langues, les littératures et les cultures romanes et slaves en contact et en divergence, № 81/1-17-8-01, approuvé par la Faculté de Philosophie de l'Université de Niš et soutenu par l'Agence universitaire de la Francophonie. 
Dans son article « L'historien et son nombril. Essai sur la périodisation du $\mathrm{XVII}^{\mathrm{e}}$ siècle », Alain Croix affirme (Croix $1998: 16$ ) que « la périodisation n'a rien d'objectif » et qu'elle est « le reflet d'une reconstruction personnelle du temps » qui repose sur une hiérarchie de facteurs, à savoir sur une conception de l'histoire. Ainsi une périodisation repose-t-elle sur un choix ou une concession idéologique (Croix 1998 : 18). Jean Rohou, dans «Plaidoyer pour une périodisation critique», ce qui est son introduction au numéro 34 de la revue thématique Littératures classiques, constate que : " toute périodisation est périodisation de quelque chose d'un certain point de vue, et non pas vérité universelle » (Rohou 1998 : 7). En plus, les catégories des sciences historiques ne sont pas aussi objectives que celle des sciences naturelles. Néanmoins, les catégories restent indispensables : pour l'organisation des observations, pour l'élaboration d'une connaissance explicative, pour la transmission des informations.

Les périodisations et les classifications littéraires créent-elles une fausse image d'une période de la création littéraire nommée une époque, d'une production poétique nommée un mouvement ou un courant littéraire, des œuvres mêmes se trouvant encadrées dans une construction datée issue de la périodisation? Si nous nous référons de nouveau au dix-septiémiste Jean Rohou : " périodiser, c'est ruiner l'irréductible originalité des moments et des œuvres » (1998:6). La périodisation littéraire suppose une synchronie artistique, à savoir l'uniformité de l'époque, et impose les temps forts d'une période. Toute synchronie poétique des moments créatifs encadrés par une période littéraire n'est qu'un tableau simplifié d'une réalité plus complexe. Dans son article « Frontières du classicisme » Emmanuel Bury propose « de nuancer toute synchronie trop mécanique par un juste sentiment de la coexistence de courants et de rythmes différents dans l'évolution » (Bury 1998 : 226). L'uniformité d'une époque n'existe que dans notre réception influencée par les théories systématisant les traits communs d'une poétique et d'une poésie, à savoir d'une époque littéraire et d'une production d'art.

Le dessein de cette recherche est d'analyser comment l'âge classique français est considéré dans l'histoire et la théorie littéraires et quel cadre temporel lui attribuent les théoriciens, de la fin du XIX ${ }^{\mathrm{e}}$ siècle - avec Gustave Lanson, et tout au long du Xx ${ }^{\mathrm{e}}$ siècle, jusqu'au début du $\mathrm{XxI}^{\mathrm{e}}$ siècle. Le présent article se propose de revaloriser les théories concernant l'âge classique français dans le dessein de susciter de nouvelles considérations sur cette époque de la littérature française. Les deux questions polémiques se posent : celle du nom du XVII ${ }^{\mathrm{e}}$ siècle littéraire et celle de son calendrier, à savoir du cadre avec des dates formant une époque désignée comme un siècle littéraire. 


\section{Le XVII ${ }^{\mathrm{e}}$ siècle littéraire entre le baroque et le classicisme}

La littérature française du XvII ${ }^{e}$ siècle est habituellement désignée comme celle de l'âge classique. Jean Rousset, inventeur du baroque, comme le nomme Emmanuel Bury, réhabilite la poésie et le théâtre dits « baroques » et incite certains théoriciens de rebaptiser le siècle du classicisme en celui du classicisme et du baroque. C'était le cas de Slobodan Vitanović dans l'étude intitulée « La littérature française du baroque et du classicisme (1598-1683) » faisant la deuxième partie du premier volume de la collection de l'histoire littéraire intitulée Littérature française (Francuska književnost, 1976) sous la direction de Branko Džakula, dans l'édition yougoslave Svjetlost de Sarajevo et Nolit de Belgrade. Vitanović affirme qu'« il est finalement clair au dernier des derniers sceptiques que la littérature française de la fin du Xvi ${ }^{\mathrm{e}}$ siècle et pendant les deux premiers tiers du XVII ${ }^{\mathrm{e}}$ siècle ne puisse être comprise sans accepter l'existence du baroque, et en plus sans lui accorder de l'attention »(Vitanović 1976 : 173). Vitanović reproche aux théoriciens littéraires d'évaluer la valeur du baroque selon les critères d'une autre poétique le considérant comme « quelque chose d'irrégulier, d'incompréhensible, de bizarre, de mauvais goût, en un mot - ce qui n'est pas classique » (1976 : 173). Robert Horville s'inscrit dans cette tradition théorique de la seconde moitié du $\mathrm{Xx}^{\mathrm{e}}$ siècle qui accentue le baroque dans les périodisations littéraires. Dans sa division chronologique du XVII ${ }^{\mathrm{e}}$ siècle littéraire en quatre périodes Horville attribue le nom de baroque aux deux premières périodes : $1^{\circ}$ la période baroque, de 1598 à $1630 ; 2^{\circ}$ la période du baroque au classicisme, de 1630 à 1661. En disciple de Rousset, Horville attribue le souffle baroque à « une conception d'un monde en transformation permanente, avide de liberté, conscient de la force des apparences » (Horville 1988 : 46). De même, Alain Croix (Croix 1998 : 25) considère-t-il le XVII ${ }^{e}$ siècle littéraire en y distinguant la France baroque des années 1580-1660 et la France classique des années 1660-1720, et en dégage « un intermède louis-quatorzien » qui sépare une France baroque d'une France des Lumières (Croix $1998: 25$ ).

Néanmoins, cette périodisation politiquement correcte, où le classicisme et le baroque cohabitent au XVII ${ }^{\mathrm{e}}$ siècle, ne demeure plus dans les études récentes. Ainsi, dans Une histoire brève de la littérature française (2015) Alain Viala désignet-il le XVII siècle littéraire comme l'« Âge classique » en expliquant que l'« on désigne communément par Âge classique français la période qui court de la fin du $\mathrm{XVI}^{\mathrm{e}}$ siècle au début du XVIII ${ }^{\mathrm{e}}$ siècle » (Viala $\left.2015: 11\right)$. Viala souligne $(2015: 12)$ que certains historiens des arts et de la littérature ont inventé la notion de baroque en estimant que le mot classique ne rendait pas bien compte des réalités du XVII ${ }^{\mathrm{e}}$ siècle. Dans son approche théorique Viala laisse de côté ces catégories qu'il juge « projetées, exogènes et polémiques ». En avouant qu'il n'y a point de terme endogène commode pour désigner l'ensemble de la période, Viala utilise le terme d'Âge 
classique au sens historique : " lorsqu'une civilisation atteint son développement le plus notable, ce moment de son histoire est qualifié de classique » (2015 : 12).

En réfutant l'école dite «baroque » de Rousset, revenons-nous aux périodisations littéraires qui dominaient la théorie et l'histoire littéraires au XIX ${ }^{\mathrm{e}}$ siècle et dans la première moitié du $\mathrm{Xx}^{\mathrm{e}}$ siècle. Selon Gustave Lanson, chez les représentants du XVI ${ }^{e}$ siècle, disparus aux environs de 1615, «nous avons vu se former tous les traits de l'esprit classique » (Lanson 1912 : 366). Ainsi, le XVII e siècle littéraire commence-t-il avec Malherbe qui définit l'idéal classique. Néanmoins, dans la production littéraire de la première moitié du siècle « règne en apparence la plus incroyable confusion » que Lanson décrit comme " des résistances, des reculs, des contradictions, des aberrations de toute nature » $(1912: 366)$. Dans son Histoire de la littérature française (1896), pour cette recherche consultée dans sa $12^{\mathrm{e}}$ édition, Lanson rassemble dans un chapitre thématique intitulé "Attardés et égarés » les auteurs suivants : D'Aubigné, ce « survivant du $16^{\mathrm{e}}$ siècle » (1912 : 366), ensuite, Maynard et Racan, les mondains de l'Hôtel de Rambouillet, Voiture et les poètes précieux, $\mathrm{M}^{\mathrm{lle}}$ de Scudéry, Saint-Aman et Scarron. La création littéraire, que Rousset baptise positivement baroque, Lanson la désigne négativement comme « une débauche d'esprit et de fantaisie » où « l'invention monstrueuse " s'associant à une " exécution hâtive, inégale, et grossière jusque dans ses finesses » $(1912: 390)$. En dépit de cette incohérence des poètes « irréguliers » et « égarés », voire marginaux, «l'instinct classique du temps l'emporte, et organise peu à peu la littérature à son image. » (1912:367).

Dans la Littérature française (1923), refondue et augmentée dans la nouvelle édition sous la direction de Pierre Martino (1948), Joseph Bédier et Paul Hazard l'on note en marge de leurs considérations historico-littéraires que les réguliers et les indépendants étaient opposés dans la première moitié du siècle, mais que l'évolution littéraire, «à travers la richesse encore confuse de l'époque de Louis XIII », allait lentement vers l'élégance classique et aboutit à la mesure et à l'unité (Bédier, Hazard 1948 : 320). Dans le Manuel des études littéraires françaises (1947), Pierre-Georges Castex et Paul Surer accentuent l'opposition entre l'exigence d'un ordre, d'une part, et, d'autre part, le goût profond de l'indépendance de la première période englobant le cadre temporel 1598-1661, qu'ils nomment «l'âge du romanesque et du baroque ». Dans ce manuel destiné aux élèves des lycées et collèges, mais qui peut être aussi utile aux étudiants, le terme de baroque est utilisé pour désigner le style mêlant " le trivial au précieux », cultivant « l'excès sous toutes ses formes », célébrant « la nature, le rêve et la nuit», s'épanouissant « dans l'inspiration lyrique» (Castex, Surer $1957: 2$ ). Ces deux coauteurs opposent au goût classique, « défini par la sobriété, la mesure et le choix », le « visage original » du baroque, qui est « une sorte de romantisme avant la lettre » (1957 : 2). Bien que l'étude soviétique Histoire de la littérature française, des origines à la Révolution française 1789 (Истиория франиузской 
литерайуры, С яревнейших времен gо Револючии 1789 і., 1946), nomme le $\mathrm{XVII}^{\mathrm{e}}$ siècle littéraire - «le classicisme », elle met en lumière le combat que cette poétique régnante menait pendant la première moitié du siècle contre les deux adversaires étant « une sorte de la Fronde dans le domaine de la littérature » : « contre la littérature galante et aristocratique du baroque », à savoir la littérature précieuse, et « contre le réalisme vulgaire» (Anisimov et al. $1946: 349$ ).

La notion de baroque, que Lanson ne connait pas, que Bédier et Hazard mentionnent sporadiquement, que Castex et Surer mettent dans le titre d'une période littéraire, André Lagarde et Laurent Michard considèrent comme adéquat « de rattacher à un mouvement d'ensemble des tendances qui paraissent jusque-là tout à fait dispersées, sinon incohérentes » (Lagarde, Michard 2010 : 12). Bien que la vogue du baroque s'étende en France depuis le dernier quart du XvI ${ }^{e}$ siècle jusque vers la fin du règne de Louis XIII, comme le souligne Lagarde et Michard dans leur anthologie et histoire littéraire (1962), « le génie français a réagi très tôt dans le sens de la discipline, de l'ordre et de la régularité » (2010 : 12-13), pour que l'époque entière soit nommée " le siècle de Louis XIV et du classicisme » (2010 : 7). Au début du $\mathrm{xxI}^{\mathrm{e}}$ siècle, de nouvelles considérations théoriques et historiques des lettres françaises reprennent l'appellation traditionnelle du XVII ${ }^{\mathrm{e}}$ siècle littéraire comme - l'Âge classique, et vont plus loin en élargissant des frontières temporelles de l'époque classique.

\section{Les frontières du classicisme et de l'Âge classique}

Pour encadrer l'Âge classique français, les théoriciens de la littérature recourent habituellement aux dates de l'histoire politique au lieu de dégager les dates littéraires d'un siècle considéré comme une époque littéraire. Castex-Surer encadrent le XVII siècle littéraire par les années 1598-1715 ; Bédier-Hazard optent pour une période classique 1594-1685 ; Lanson-Tuffrau (1931, réédité en 1945) proposent les années 1594-1715 ; Lagarde-Michard choisissent le cadre 1610-1715 ; Robert Harville place la période classique entre 1661 et 1685. Dans toutes ces histoires littéraires les dates indiquées ne représentent que des événements politiques : le couronnement d'Henri IV (1594) et sa mort (1610), la promulgation de l'Édit de Nantes (1598) et sa révocation (1685), le début du règne personnel de Louis XIV (1661) et sa mort (1715). Dans la Littérature française, sous la direction de Claude Pichois, l'âge classique s'étale de 1624 à 1720, en se divisant en trois périodes : 1624-1660 (Adam 1968), 1660-1680 (Clarac 1969), 1680-1720 (Pomeau 1971). La première date est politique, celle du début du ministère Richelieu; en revanche, la date de 1720, pour l'histoire politique «n'a pas de signification particulière » (Ehrard $1974: 7)$.

Par habitude, les théoriciens arrondissent les dates d'une période littéraire. Les années 1660-1680 comme celles du classicisme au sens pur figurent dans la 
plupart des études classiques françaises. Dans la Littérature française de Larousse (1972) la période de 1660 à 1680 est nommée « la Grande Époque », précédée par celle de la « Naissance du classicisme » de 1630 à 1660. Cette histoire de la littérature française souligne des parallèles politico-littéraires entre l'âge d'or du classicisme (1660-1680) et la première phase du règne personnel du Roi Soleil (1661-1685). Mais, cette édition de Larousse constate que la doctrine classique a atteint son point d'équilibre « en $1660 »$ (Adam et al. 1972:184), sans expliquer pourquoi en 1660 et non pas en 1659 ou en 1661. En réfutant la pratique des théoriciens de l'histoire littéraire de pousser la complaisance jusqu'à arrondir les dates des périodes constituant une époque, Jean Rohou se demande s'il s'agit « de flatter la paresse des lecteurs ou d'apporter des informations justes » $(1998: 8)$. Ce dix-septiémiste français ne trouve aucun événement d'importance littéraire qui se produit en 1660. En revanche, en 1659 se produit le retour de Corneille au théâtre, Molière met en scène Les Précieuses ridicules, La Fontaine écrit Le Songe de Vaux, Bossuet s'installe à Paris. "Ces événements préparent l'avenir », constate Rohou (1998: 8). Ou, l'année 1562 : Colbert charge Chapelain de proposer les auteurs, artistes et savants qui recevront une gratification ; paraissent les premiers chefs-d'œuvre de l'esthétique plus tard qualifiée de classique - La Princesse de Montpensier de Marie-Madeleine de La Fayette, L'École des femmes de Molière, la tragédie Sertorius de Pierre Corneille, les sermons de Bossuet Le carême du Louvre, La Logique ou l'art de penser d'Antoine Arnauld et Pierre Nicole de Port-Royal. Mais en 1660, que s'est-il donc passé ? À cette question rhétorique suit la réponse : «C'est seulement la date que choisit notre paresse, ou celle que nous imposent les services commerciaux des éditeurs » (Rohou 1998 : 9). Jean Rohou a offert un tableau du XVII ${ }^{\mathrm{e}}$ siècle littéraire en cinq périodes thématiques dont les dates-frontières ne sont pas arrondies ni forcément réduites à une annéelimite entre deux périodes. Cette périodisation figure dans son Histoire de la littérature française du XVII siècle (Rohou 1989) : la première période - domination du lyrisme (de 1598-1606 à 1624-1628); la deuxième période - discipline et dramaturgie (1628-1642 environ); la troisième période - romanesque et parodie (de 1643 à 1659 environ); la quatrième période - le classicisme (1659-1662 à 1679-1681) ; la cinquième période - l'analyse critique (de 1682 à 1703-1706).

Rohou prêche d'écarter l'idée de chercher « les frontières théoriques »du classicisme, parce qu'il s'agit d'un mythe a posteriori, de renoncer aux « frontières historiques ", parce qu'il est difficile de les tracer avec objectivité, et d'avouer que la dynamique même de la vie littéraire nous échappe (Rohou 1998 : 9). Ce sont les raisons pour lesquelles Emmanuel Bury opte pour « les frontières polémiques » parce que l'élaboration du classicisme gagne beaucoup à être comprise dans le cadre d'une historiographie de querelles : des premières Lettres de Guez de Balzac (1624) à la querelle des Anciens et des Modernes (1687), « tous les points de la doctrine classique ont été formulés au moment où ils étaient atta- 
qués, défendus, justifiés » (Bury 1998 : 230). Bury instaure ainsi les temps forts des frontières polémiques dans la période classique qu'il encadre dans les années 1624-1687 : l'année 1637 avec la querelle du Cid, la crise de 1650 autour de Voiture et de Balzac pour proclamer la légitimité d'une littérature mondaine, l'année 1663 avec la querelle de L'École des femmes, l'année 1678 avec les débats autour La princesse de Clèves affirmant la liberté du roman.

Le classicisme au sens restreint comme la grande époque ne couvrant que les deux décennies du XVII ${ }^{e}$ siècle diffère de la notion d'Âge classique. Utilisé pour la première fois au XIX ${ }^{\mathrm{e}}$ siècle, par exemple chez Hyppolite Taine réunissant en un même ensemble les XVII ${ }^{\mathrm{e}}$ et XVIII ${ }^{\mathrm{e}}$ siècles, le concept de l'Âge classique sera repris par la plupart des chercheurs au début du $\mathrm{xxI}^{\mathrm{e}}$ siècle. Alain Viala, qui encadre le XVII ${ }^{e}$ siècle littéraire de 1598 à 1715 , suggère que l'« on pourrait tirer l'Âge classique français jusque tard dans le XVIII ${ }^{e}$ siècle puisque, à bien des égards, le siècle appelé des Lumières se développe en s'appuyant sur les acquis du précédent » (Viala 2015 : 13). L'Histoire de la France littéraire en trois gros volumes (2006) repense l'ensemble des lettres françaises en trois grandes époques : " Naissances, Renaissances », car la France littéraire au Moyen Âge et au XVI ${ }^{\mathrm{e}}$ siècle « est d'abord un mosaïque de renaissances » (Darmon, Delon 2006 : XII) ; ensuite, "Classicismes », en pluriel, englobant les XVII ${ }^{e}$ et XVIII" siècles ; et enfin, « Modernités » aux XIX et $\mathrm{XX}^{\mathrm{e}}$ siècles. Néanmoins, en se référant au classicisme au sens stricte, Jean-Charles Darmon et Michel Delon, qui dirigent le deuxième tome de l'édition (Classicisme, XVII $-X V I I I^{e}$ siècle), précisent que nous pouvons « parler d'âge classique en y inscrivant l'ensemble de cette période de 1650 à $1750 »(2006: 11)$. Ainsi la notion est-elle aujourd'hui « en mouvement entre des définitions chronologiques intensive (une vingtaine d'années entre 1660 et 1680) ou extensive (les $\mathrm{XVII}^{\mathrm{e}}$ et $\mathrm{XVIII}$ e siècles, de la fondation de l'Académie française (1635) au discours de Rivarol sur l'universalité de la langue française (1784) » (2006 : 27).

Dans Le classicisme (2015), Alain Génetiot élargit les frontières de l'Âge classique « de la Renaissance qui refonde l'héritage antique au romantisme qui jette les bases théoriques de sa remise en question » (Génetiot 2015 : 61). Ainsi, le XVIII ${ }^{e}$ siècle est-elle en grande partie « un second classicisme ou un post-classicisme », notamment chez un Voltaire, conclut Génetiot (2015 : 73). Non seulement dans le domaine de poétique, mais aussi dans celui de la morale, certains théoriciens trouvent que les classiques du XVII ${ }^{\mathrm{e}}$ siècle sont compatibles avec les philosophes des Lumières. (2015 : 119). Zékian révèle que Lémontey était l'un des premiers d'avoir éclairé « le caractère révolutionnaire » du XVII ${ }^{\mathrm{e}}$ siècle (Zékian 2012 : 59). Sous le dehors d'une étroite subordination des auteurs classique au roi, il se produit une " progressive émergence d'une souveraineté parallèle » des auteurs classiques par rapport au souverain (2012 : 63). Repensé de la sorte, le génie du XVII ${ }^{\mathrm{e}}$ siècle est transformé en penseur hardi du XVIII ${ }^{\mathrm{e}}$ siècle, et « les cent 
cinquante années précédant la Révolution française scandent le développement d'un seul et même processus » (2012:63).

\section{En guise de conclusion}

Dans la préface de leur Manuel des études littéraires françaises (Castex, Surer 1957 : VI), les coauteurs constatent que « l'histoire littéraire se renouvelle constamment », ils conseillent que « chaque génération révise et modifie les jugements de celle qui l'a précédée », ils préviennent de "ne jamais céder aux caprices de la mode », ni d'entretenir des préjugés d'une tradition imposée. Cessons donc de maquiller en siècle de Louis XIV le XVII ${ }^{e}$ siècle littéraire ! N'attribuons plus au pseudo-roi Soleil les grands auteurs! Renonçons à la pratique théorique d'arrondir les dates des époques littéraires! Ne recourons point aux événements politiques pour dater des mouvements littéraires ! C'est ainsi que le renversement de perspective sera complet.

Ce qui demeure est le génie classique d'une grande époque, à savoir une valeur considérée comme impérissable. Concluons avec Génetiot (lui-même se référant à Gadamer) que l'âge classique est un moment ancré dans l'histoire littéraire française, mais que le classicisme est une valeur concernant la littérarité d'une œuvre, ce qui est aussi la question posée à la littérature et autour de laquelle s'est construite la modernité. En synonyme de perfection, « le classicisme est ce qui survit au passage du temps, ce qui n'a pas besoin de médiation historique parce que, dans sa modalité même d'être historique, il est intemporel » (Génetiot 2005 : 57) ; ou, exprimé par les mots empruntés à Gadamer : une œuvre de classique est « dans une sorte de présence intemporelle, contemporaine de tout présent » (Gadamer 1996 : 309).

\section{Références bibliographiques}

Adam 1968 : A. Adam, L’Âge classique 1624-1660, tome I, collection Littérature française, dirigée par C. Pichois, vol. VI, Paris : Arthaud.

Adam et al. 1972 : A. Adam, G. Lerminier et É. Morot-Sir, Littérature française. Des origines à la fin du XVIII siècle, Paris : Larousse.

Anisimov et al. 1946 : И. И. Анисимов, С. С. Мокульсккий, А. А. Смирнов, Истиория франиузской лииеерайуры, йом 1, С яревнейших времен до Революиии 1789 i., Академии Наук СССР: Москва - Ленинград.

Bédier, Hazard 1949 : J. Bédier et P. Hazard, Littérature française, tome premier, nouvelle édition refondue et augmentée sous la direction de Pierre Martino, Paris : Librairie Larousse.

Bury 1998 : E. Bury, « Frontières du classicisme », Littératures classiques, $\mathrm{n}^{\circ} 34$, Paris : Honoré Champion, 217-236. 
Castex, Surer 1957 : P.-G. Castex et P. Surer, Manuel des études littéraires françaises : Le XVII siècle, Paris : Hachette.

Clarac 1969 : P. Clarac, L'Âge classique 1660-1680, tome II, collection Littérature française, dirigée par C. Pichois, vol. VII, Paris : Arthaud.

Croix 1998 : A. Croix, «L'historien et son nombril. Essai sur la périodisation du XVII siècle », Littératures classiques, $n^{\circ}$ 34, Paris : Honoré Champion, 15-25.

Darmon, Delon 2006 : J.-C. Darmon et M. Delon, Histoire de la France littéraire. Classicismes, $X V I I^{e}-X V I I I^{e}$ siècle, Paris : PUF.

Ehrard 1974 : J. Ehrard, Le XVIII siècle, 1720-1750, tome I, collection Littérature française, dirigée par C. Pichois, vol. IX, Paris : Arthaud.

Gadamer 1996 : H.-G. Gadamer, Vérité et méthode, Paris : Le Seuil.

Génetiot 2005 : A. Génetiot, Le classicisme, Paris : PUF.

Horville 1988 : R. Horville, Itinéraires littéraires - XVII siècle, Paris : Hatier.

Lagarde, Michard 2010 : A. Lagarde et Laurent Michard, Collection littéraire - Le XVII siècle. Les grands auteurs français, anthologie et histoire littéraire, Paris : Bordas.

Lanson 1912 : G. Lanson, Histoire de la littérature française, Paris : Hachette.

Lanson, Tuffrau 1945 : G. Lanson et P. Tuffrau, Manuel illustré d'histoire de la littérature française, London : George G. Harrap \& Co. LTD.

Pomeau 1971 : R. Pomeau, L'Âge classique 1680-1720, tome III, collection Littérature française, dirigée par C. Pichois, vol. viII, Paris : Arthaud.

Rohou 1989 : J. Rohou, Histoire de la littérature française du XVII siècle, Paris : Nathan.

Rohou 1998 : J. Rohou, « Plaidoyer pour une périodisation critique », Littératures classiques, $\mathrm{n}^{\circ} 34$, Paris : Honoré Champion, 5-12.

Viala 2015 : A. Viala, Une histoire brève de la littérature française : L’Âge classique et les Lumières, Paris : PUF.

Vitanović 1976 : S. Vitanović, „Francuska književnost baroka i klasicizma (1598-1683)“, in Francuska književnost (dir. B. Džakula), Beograd-Sarajevo: Svjetlost/Nolit, $165-270$.

Zékian 2012 : S. Zékian, L'invention des classiques, Paris : CNRS Éditions. 
Нермин Вучељ

\section{Француска класична епоха у књижевним периодизацијама}

Циљ дијахронијске класификације књижевне продукције, што јесте историјска периодизација књижевности, у томе је да се књижевност лакше опише и учини разумљивом у својој свеукупности, од познатих почетака песничког стваралаштва до данас. Тако књижевне периодизације служе томе да се теоријски изведу опште уметничке карактеристике установљених стваралачких епоха и разврстаних књижевних периода. Свака периодизација је, ипак, теоријска конвенција, тиме онда релативна и променљива, што се следствено односи и на класификацију француског књижевног XVII века, епохе која се уобичајено назива класичном. Намера је да се у овом истраживању аналитички претресе питање како је француског класично доба разматрано у књижевним теоријама и историјама и који су му календарски оквири одређивани, и у том циљу корпус чине теоријске студије од краја ХIX века, с Лансоном (Lanson, 1912), оне у хх веку - Bédier-Hazard (1923, 1948), CastexSurer (1947), Lagarde-Michard (1962), затим, Артоова (Arthaud) књижевна колекција (Adam-Clarac-Pomeau, 1968-1971), Кюижевни йуиеви (Itinéraires littéraires, Horville, 1988), Роуов књижевноисторијски преглед (Rohou, 1989), све до студија на почетку ххі века - Жентиоовог Класицизма (Le Classicisme, Génetiot, 2005), Иcйорије књижевне Франиуске групе аутора (Histoire de la France littéraire, 2006), те Зекјанове (Zékian, 2012) и Вјалине (Viala, 2015) студије. Овај рад се реферише и на књижевноисторијска разматрања из епохе Совјетског Савеза (Исйория франиуз-

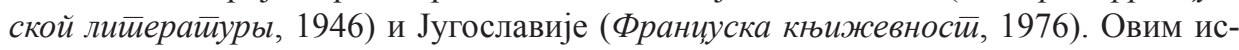
траживањем се желе преиспитати теоријске студије о француској класичној епохи и подстакнути нова критичка разматрања француског књижевног XVII века.

Кључне речи: француска класична епоха, XVII век, класицизам, књижевна периодизација, теорија књижевности, књижевна историја. 